\title{
LUNG DERECRUITMENT DURING GENERAL ANAESTHESIA WITH CONSTANT POSITIVE END-EXPIRATORY PRESSURE
}

\author{
Ribeiro, R. A.; Gonçalves, A. S.; Macruz, T. A.; Torsani, V.; Ferez, D.; Falcão, L. F. R. \\ Discipline of Anaesthesiology, Pain and Critical Care Medicine, Federal University of São Paulo, Brazil
}

\section{INTRODUTCTION}

The literature is controversy regarding the use of positive endexpiratory pressures (PEEP), failing to demonstrate, so far, reduction of postoperative pulmonary complications (PPCs). This pilot study aims to evaluate the behavior of pulmonary aeration in surgery under general anesthesia and mechanical ventilation with continuous use of PEEP.

\section{METHODS}

Pilot study with female patient, 39 years-old, ASA P2, underwent facial plastic surgery with general anesthesia during 9 hours and 30 minutes. Held mechanical ventilation (MV) volume-controlled, $\mathrm{V}_{\mathrm{T}} 8 \mathrm{ml} / \mathrm{kg}$ of predicted body weight, PEEP $5 \mathrm{cmH}_{2} \mathrm{O}, \mathrm{FiO}_{2} 50 \%$ and respiratory rate to keep $\mathrm{ETCO}_{2}$ between 35 and $45 \mathrm{mmHg}$. Ventilation parameters (including $\mathrm{V}_{\mathrm{T}}$ and PEEP) were kept constant throughout the anesthesia. It was not performed recruitment maneuvers. Regional lung aeration (dependent and non-dependent), inferred by the end-expiratory lung volume (EELV) was evaluated in real time with electrical impedance tomography (Enlight ${ }^{\circledR}$, São Paulo, Brazil) during all procedure.

\section{RESULTS}

It was observed gradual reduction of EELV, with marked loss $(487 \mathrm{~mL}$ ) two minutes after anaesthetic induction and MV (Figure 1). After 1 hour under MV, EELV was reduced in $1224 \mathrm{ml}$. After this period, there was a decrease in the fall rate of the EELV until it reaches a loss of $2021 \mathrm{ml}$ after 8 hours of MV. Dependent region aeration showed marked drop compared to the nondependent region (Figure 1 and 2).

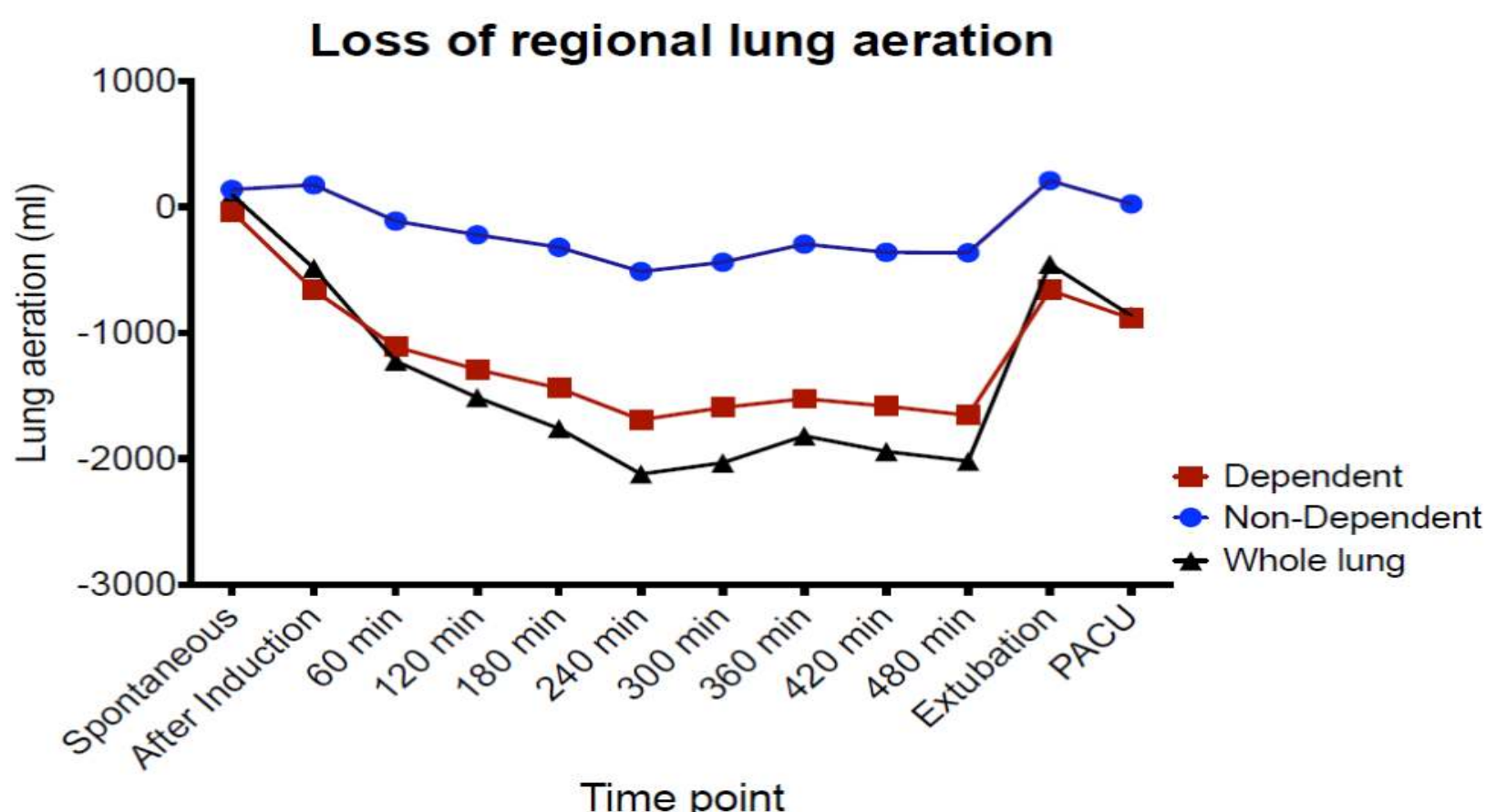

Figure 1. DEPENDENT AND NON-DEPENDENT LUNG AERATION

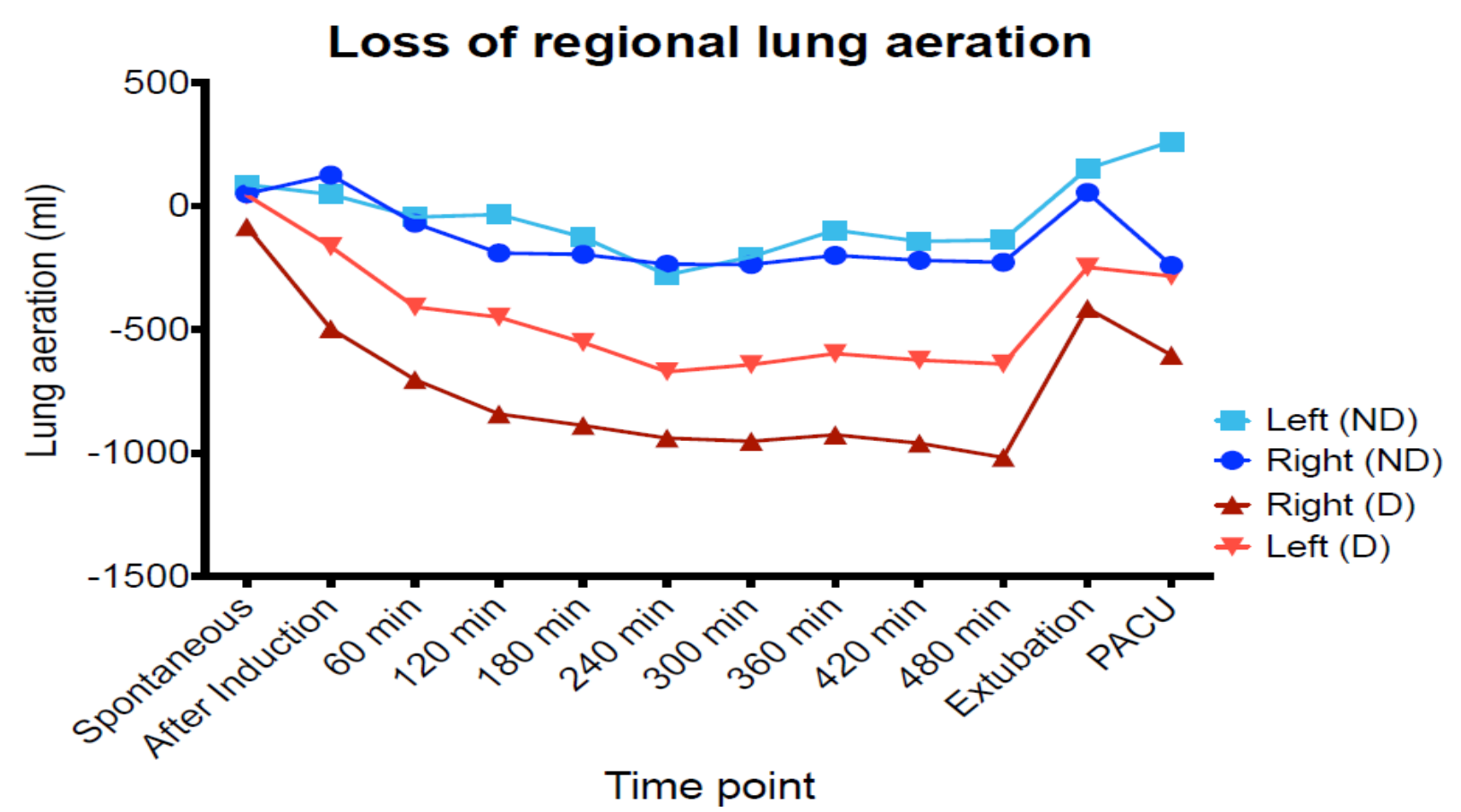

Figure 2. REGIONAL LUNG AERATION
At the end of surgery, the loss in the dependent region was $1,656 \mathrm{ml}$, or $82 \%$ of the total decrease of the EELV. The $\Delta Z\left(V_{T}\right)$ did not change significantly since it was kept constant all ventilation parameters. However, the distribution of ventilation between the regions non-dependent / dependent change after induction, from $44 \% / 56 \%$ to $64 \%$ / $36 \%$. Lung compliance (Crs) tended to decrease during the intraoperative.

\begin{tabular}{lccccc}
\multicolumn{5}{c}{ Table. Lung aeration measurements before, during and after mechanical ventilation } \\
\hline \multicolumn{5}{c}{ NON DEPENDENT } & \multicolumn{2}{c}{ DEPENDENT } & p-value \\
\hline Spontaneous & 136.8 & \pm 26.9 & -39.1 & \pm 28.5 & 0.0001 \\
After induction & 173.9 & \pm 12.5 & -660.7 & \pm 9.9 & 0.0001 \\
$\mathbf{6 0}$ min & -113.8 & \pm 21.7 & -1110.5 & \pm 17.6 & 0.0001 \\
$\mathbf{1 2 0}$ min & -223.3 & \pm 9.7 & -1290.8 & \pm 4.7 & 0.0001 \\
$\mathbf{1 8 0}$ min & -321.5 & \pm 23.9 & -1440.3 & \pm 10.8 & 0.0001 \\
$\mathbf{2 4 0}$ min & -513.1 & \pm 12.2 & -1609.5 & \pm 9.2 & 0.0001 \\
$\mathbf{3 0 0}$ min & -440.5 & \pm 27.1 & -1593.0 & \pm 9.5 & 0.0001 \\
$\mathbf{3 6 0}$ min & -296.5 & \pm 16.9 & -1522.2 & \pm 6.5 & 0.0001 \\
$\mathbf{4 2 0}$ min & -361.8 & \pm 6.6 & -1582.6 & \pm 6.4 & 0.0001 \\
$\mathbf{4 8 0}$ min & -364.5 & \pm 17.4 & -1656.5 & \pm 6.8 & 0.0001 \\
Extubation & 207.3 & \pm 34.1 & -661.2 & \pm 24.0 & 0.0001 \\
PACU & 22.4 & \pm 70.9 & -886.6 & \pm 68.0 & 0.0001 \\
\hline * Variables
\end{tabular}

After emergence from anaesthesia, there was a self-recruiting of $1360 \mathrm{ml}$ during spontaneous ventilation. At discharge from PACU, dependent region still showed a decrease of $886 \mathrm{ml}$ and non-dependent region an increase of $22 \mathrm{~mL}$ compared to preoperative values. A repeated measured analysis of variance (ANOVA) was performed to evaluate the loss of lung aeration among time-points (after intubation until the end of the surgery). Follow up comparisons indicated that each pairwise difference was significant, $p=0.013$ (non-dependent region) and $p=0.003$ (dependent region). There was a significant lost of lung aeration over time, despite the constant PEEP.

\section{Figure 3. LUNG AERATION AT DIFFERENT TIME POINTS}

Functional lung image acquired from EIT offline analysis. Regions with higher air represented in white, regions with less air in dark blue, regions not aerated in gray.

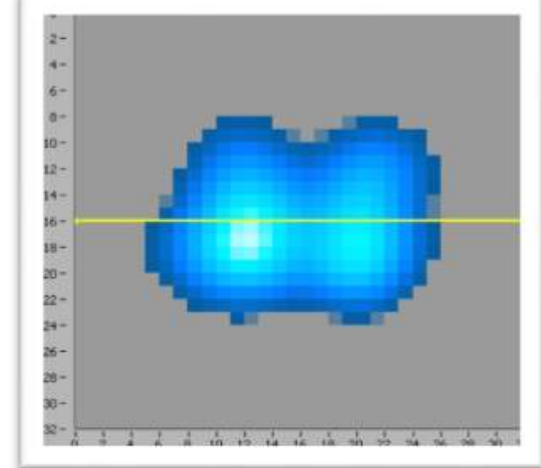

A: Baseline

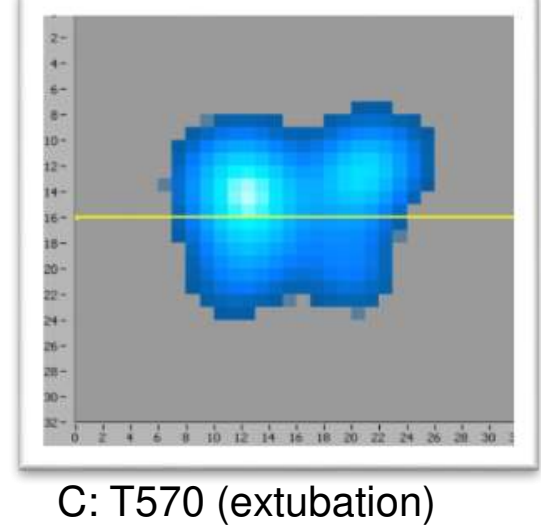

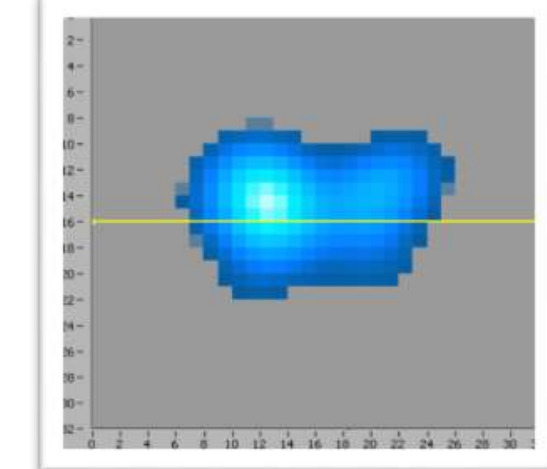

B: T0 (after intubation)

\section{CONCLUSIONS}

Anaesthesia causes abrupt loss of lung aeration and also causes ventilation redistribution from dependent to nondependent region. PEEP of $5 \mathrm{cmH}_{2} \mathrm{O}$ was ineffective to maintain lung volume. Loss aeration occurs mainly in dependent region and it is more pronounced in the first hour of mechanical ventilation. 